\title{
Adsorption Characteristics of Banana Peel in the Removal of Dyes from Textile Effluent
}

\author{
Maimuna Akter ${ }^{1,+}$, Fahim Bin Abdur Rahman ${ }^{1,2, *,+}\left(\mathbb{D}\right.$, M. Zainal Abedin ${ }^{1}$ and S M Fijul Kabir ${ }^{3,4, *(\mathbb{D})}$ \\ 1 Department of Environmental Management, Independent University-Bangladesh, Dhaka 1229, Bangladesh; \\ maimuna_041@yahoo.com (M.A.); zabedinbd.iub.bd@gmail.com (M.Z.A.) \\ 2 Department of Chemical Engineering, University of South Carolina, Columbia, SC 29208, USA \\ 3 Wilson College of Textiles, North Carolina State University, Raleigh, NC 27695, USA \\ 4 Department of Textile Engineering, National Institute of Textile Engineering and Research, \\ Savar, Dhaka 1350, Bangladesh \\ * Correspondence: frahman@email.sc.edu (F.B.A.R.); skabir@ncsu.edu (S.M.F.K.) \\ + These authors have contributed equally.
}

Citation: Akter, M.; Rahman, F.B.A.; Abedin, M.Z.; Kabir, S.M.F. Adsorption Characteristics of Banana Peel in the Removal of Dyes from Textile Effluent. Textiles 2021, 1, 361-375. https:// doi.org/10.3390/textiles1020018

Academic Editor: Marta Gmurek

Received: 29 May 2021

Accepted: 7 September 2021

Published: 10 September 2021

Publisher's Note: MDPI stays neutral with regard to jurisdictional claims in published maps and institutional affiliations.

Copyright: (c) 2021 by the authors. Licensee MDPI, Basel, Switzerland. This article is an open access article distributed under the terms and conditions of the Creative Commons Attribution (CC BY) license (https:// creativecommons.org/licenses/by/ $4.0 /)$.

\begin{abstract}
Disposal of reactive dye contaminants in surface waters causes serious health risks to the aquatic living bodies and populations adjacent to the polluted water sources. This study investigated the applicability of banana peels to remediate water contamination with reactive dyes used in the textile industry. A set of batch experiments was conducted using a standard dye solution to determine optimum adsorption parameters, and these parameters were used for the removal of dyes from actual wastewater. Fitting experimental data into the isotherm and kinetic models suggested monolayer dye adsorption with chemisorption rate-limiting step. The maximum adsorption found from modeling results was $28.8 \mathrm{mg} / \mathrm{g}$. Fourier transformed infrared (FTIR) spectra revealed the existence of hydroxyl, amine and carboxylic groups, contributing to high adsorption of dye molecules onto the adsorbent surface. About $93 \%$ of the dyes from the standard solution were removed at optimum conditions ( $\mathrm{pH}-7.0$, initial dye concentration $-100 \mathrm{mg} / \mathrm{L}$, contact time $-60 \mathrm{~min}$, and adsorbent dose $-0.5 \mathrm{~g}$ ) while this value was $84.2 \%$ for industrial textile wastewater. This difference was mainly attributed to the composition difference between the solutions. However, the removal efficiency for actual wastewater is still significant, indicating the high potentiality of banana peel removing dyes from textile effluent. Furthermore, desorption studies showed about $95 \%$ of banana peel can be recovered with simple acid-base treatment.
\end{abstract}

Keywords: adsorption kinetics; banana peel; dye removal; isotherms; textile wastewater

\section{Introduction}

In the current scenario of rising populations and increasing industrial activities, water pollution causes significant destruction in the ecosystem and creates a potential threat to water security as only about $0.03 \%$ of global water resources are currently used for human activities. Direct disposal of untreated or inadequately treated industrial effluent into different water sources has been identified as the primary cause of present water pollution [1-3]. Textile dyeing, for instance, is pinpointed as one of the most polluting sectors that releases about 5000 10,000 tons of different reactive dyes each year, contributing about $17-20 \%$ of industrial water pollution [3-5]. Most of these dyes limit the access of sunlight into the water, causing serious health risks to the aquatic living bodies and populations adjacent to the polluted water sources, thus highlighting the need for proper treatment of textile effluents that protects both the ecosystem and the environment $[3,6]$.

Adsorption is the most common and well-developed technique compared to conventional methods employed for dye removal from textile wastewater due to its ease in process design and operation, low-cost, and high efficiency, even for highly concentrated dye solutions $[7,8]$. Moreover, the easy availability and biodegradability of adsorbent 
materials are an extra feature of the adsorption method in removing dyes from the wastewater [9]. Activated carbons and numerous organic resins have achieved amazing success as adsorbents in dye removal, however, the excessive cost of these materials impedes the widespread implementation of adsorption processes, driving researchers to seek alternative adsorbents that can provide the desired level of performance [10]. Recent studies have shown significant improvements in the cost-effectiveness of the adsorption process through the effective substitution of the standard materials by relatively low-cost and environmentally-friendly biowaste-derived adsorbents [10-13]. Previous studies have also reported that these bio-adsorbents display excellent performance in the removal of dyes [14] and heavy metals [15] from textile manufacturing effluents. These findings have inspired the development of cost-effective, environmentally sound, and efficient adsorbents to remove hazardous dyes from textile wastewater.

Banana peel has attracted attention among all other adsorbents because of its yearround availability throughout the world. The existence of different functional groups in banana peel allows the high sorption of different anionic and cationic compounds onto the surface-active sites [16]. However, most of the available banana peel is underutilized and trashed as bio-waste despite its high potential to remove heavy metals [17], pharmaceutical compounds [18], radioactive elements [19], phenolic compounds [20], etc. as disclosed in many recent research works. Although the adsorption of the dyes onto banana peel was previously studied [21-27], the potential of banana peel in treating actual textile wastewater has yet to be reported. Most of the current research has highlighted the applicability of banana peel for removal of a specific dye from a standard solution, but no effort is found in literature to the best of the authors' knowledge that was extended for the removal of different dyes from industrial wastewater. The optimum adsorption parameters determined using a mixture of dye solutions has been applied to remove dyes from textile effluent containing the same dyes. In addition to that, numerous adsorbents derived from banana peel also showed improved dye removal efficiency but have not still been employed in commercial applications due to economic reasons [28]. Therefore, the proper investigation of the use of natural banana peel for efficient water decontamination in the industrial scale is in demand.

Reactive dyes are some of the most utilized dyes for cotton coloration, and the industrial discharge of reactive dyes is increasing enormously. This work utilized natural banana peel as bio-adsorbent to remove reactive dyes from textile effluent through a set of batch adsorption processes. The adsorption performances of banana peel were tested for variable solution $\mathrm{pH}$, adsorbent dose, initial dye concentration, and contact time, followed by FTIR characterization of the banana peel. The initial investigations were done for a standard solution to determine the optimum adsorption parameters, which were later employed in actual wastewater treatment. The experimental adsorption data were precisely fitted with isotherm and kinetic models to demonstrate the adsorption behavior of banana peel for the removal of the dyes from textile wastewater.

\section{Materials and Methods}

\subsection{Chemicals and Materials}

The banana peel was collected from a local fruit market. The wastewater and the powder of three reactive dyes, which are commercially known as Deazol Black B EAN, Deafiz Red ME 6BL, and Firstfix Yellow 3RS were collected from a well-known textile dyeing unit located in Gazipur, Bangladesh. As the company only disclosed the commercial names of these dyes, the exact chemical structures were unknown in this study. However, the chemical structure of some of other commercially available dyes with similar generic groups are shown in Figure 1. Hydrochloric acid $(\mathrm{HCl})$ and sodium hydroxide $(\mathrm{NaOH})$, both supplied by Merck (Darmstadt, Germany), were used without further purification to adjust the $\mathrm{pH}$ of the solutions. 


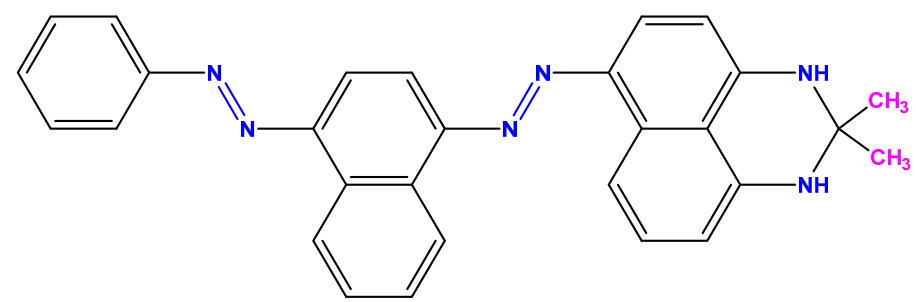

(a)

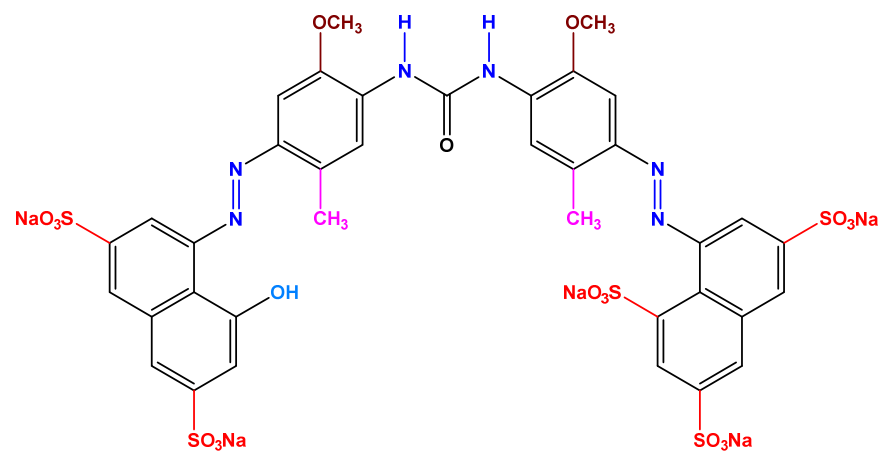

(b)

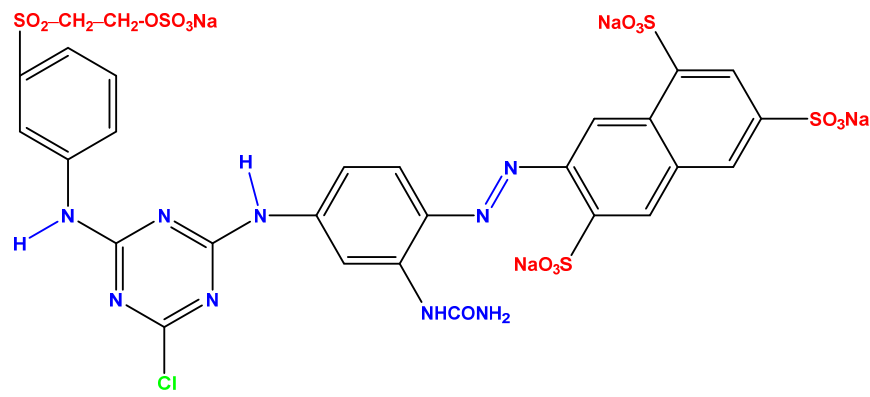

(c)

Figure 1. Chemical structure of different reactive dyes: (a) Sudan Black B, (b) Direct Red 6BL, and (c) Reactive Yellow 3RS with similar generic name as Deazol Black B EAN, Deafiz Red ME 6BL, and Firstfix Yellow 3RS, respectively.

\subsection{Adsorbent Preparation}

The banana peels were subsequently sliced into small fragments, washed, dried, crushed, and sieved before using for the adsorption treatment. The peels were washed with deionized water (DI-water) to eliminate adhering dirt particles and dried in ambient conditions for $48 \mathrm{~h}$ followed by drying at $80^{\circ} \mathrm{C}$ for $8 \mathrm{~h}$ in a 3606-1CE vacuum oven. The dried peels were grounded in HR2118 blender (Phillips, Toa Payoh, Singapore) sieved using 100 mesh size $(149 \mu \mathrm{m})$ and stored in an airtight polythene container.

\subsection{Chemical Analysis}

A DR/4000U UV-vis spectrophotometer (HACH, Loveland, CO, USA) was used to estimate the dye concentration in the solutions. The $\mathrm{pH}$ of the solutions was measured using a Hach-Sension-MM156 instrument, a portable multiparameter meter equipped with a calibrated $\mathrm{pH}$ glass electrode. A LMS-1003 magnetic stirrer (LabTech, Hopkinton, MA, USA) was used to maintain the homogeneity of dyes in the solutions. The coexisting functional groups in banana peel were identified by a IR Tracer-100 FTIR system (Shimadzu, Tokyo, Japan) equipped with a high sensitivity mercury-cadmium-telluride (MCT) detector. The equipment was integrated with the LabSolutions IR software for peak analysis. Before recording FTIR spectra, the samples were uniformly mixed with potassium bromide $(\mathrm{KBr})$ with a weight ratio of 1:100 (adsorbent: $\mathrm{KBr}$ ). The spectra were recorded for the wavenumbers ranged from 4000 to $400 \mathrm{~cm}^{-1}$. 


\subsection{Standard Solution and Calibration Curve}

A standard solution, in which the concentrations of its constituent elements are precisely known, was used to determine the optimum adsorption parameters $(\mathrm{pH}$, adsorption time, initial dye concentration, banana peel dosages, etc.) for textile wastewater treatment. The solution was prepared by dissolving an equal amount of three dyes (mentioned above) in DI-water. It was hypothesized that an equal amount of these three dyes remained in actual textile effluent. The stock solution (standard solution) was yielded by adding $1 \mathrm{~g}$ of each dye in a volumetric flask containing $2 \mathrm{~L}$ of DI-water. Afterward, the stock solution was stirred in a magnetic stirrer for $60 \mathrm{~min}$ with a rotational speed (S) of $180 \mathrm{rpm}$ to obtain homogeneous dye composition.

The absorbance of the standard solution was calibrated against solution concentrations using a wavelength at which maximum adsorption occurred $\left(\lambda_{\max }\right)$. The absorbance of the collected wastewater was plotted as a function of wavelengths, which provided the $\lambda_{\max }$ value at $601 \mathrm{~nm}$ (Figure 2a). All further spectrophotometric measurements in this study used this $\lambda_{\max }$ value. To perform the calibration study, the stock solution was further diluted to a set of concentrations ranging from 25 to $225 \mathrm{mg} / \mathrm{L}$ with $\mathrm{pH} \sim 7$. The absorbance of each solution was measured at room temperature $\left(\mathrm{T} \sim 25^{\circ} \mathrm{C}\right)$ and plotted against the concentrations (Figure 2b). The experimental data were precisely fit in a straight line with a linear regression coefficient $\left(R^{2}\right)$ of 0.9996 , thus allowing to assume a constant molar absorbability throughout the concentration range.
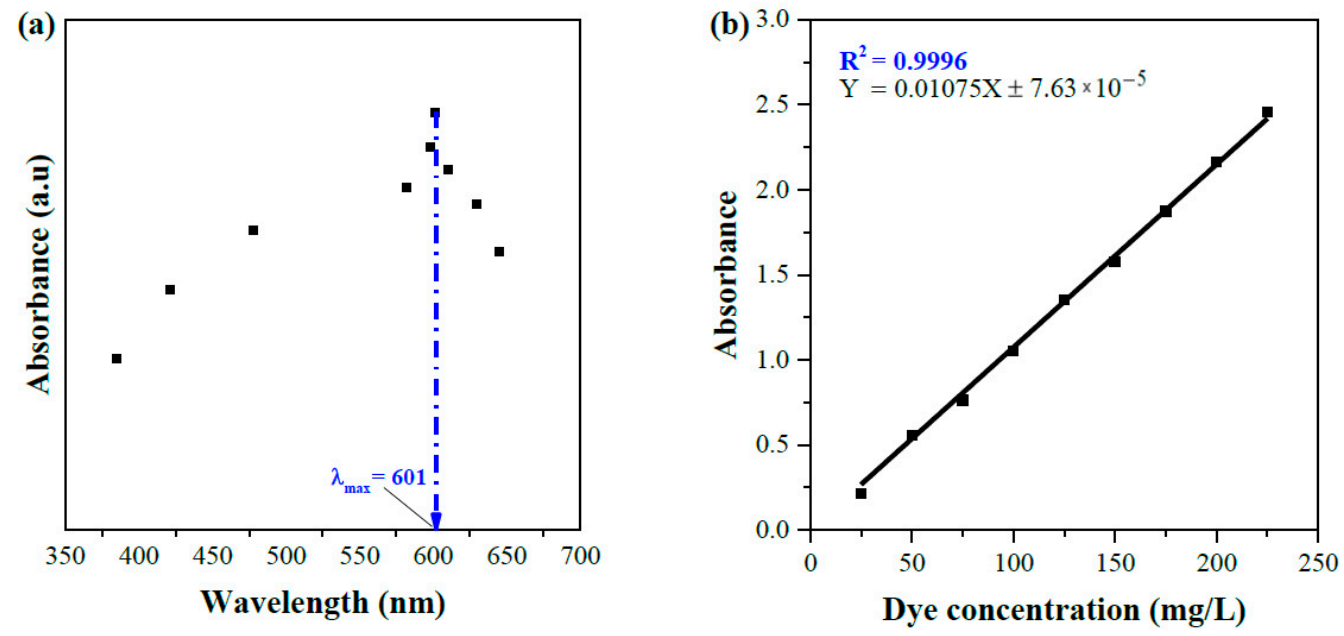

Figure 2. (a) Determination of wavelength for maximum absorption; (b) calibration curve of standard dye solution at $\lambda_{\max }=601 \mathrm{~nm}, \mathrm{pH} \sim 7$, and $\mathrm{T}=25^{\circ} \mathrm{C}$.

\subsection{Adsorption Study}

The batch experiments were conducted to investigate the adsorption behavior of banana peel in the removal of dyes from textile effluent. Before employing banana peel to remove dyes from actual wastewater, all adsorption parameters were optimized using the standard solution (for details of the preparation of standard solution see Section 2.4). To find the optimum $\mathrm{pH}$ at which maximum adsorption occurred, three different amounts of adsorbent $(0.5,0.75$, and $1.0 \mathrm{~g})$ were added in amber bottles containing $250 \mathrm{~mL}$ of a dye solution $(50 \mathrm{mg} / \mathrm{L})$ at $\mathrm{pH}$ between 2.0 and 10.0. Then, the mixtures were agitated using a magnetic stirrer for an hour with a speed of $180 \mathrm{rpm}$ at $25^{\circ} \mathrm{C}$ followed by filtration using Whatman No. 1 filter paper. The filtrated solutions were immediately analyzed by the UV-Vis spectrophotometer to estimate the final concentration of the investigated solutions using the calibration curve. In determining the effects of adsorbent dose, different amounts of banana peel $\left(\mathrm{M}_{\mathrm{ads}}\right)$ ranging from 0.1 to $0.8 \mathrm{~g}$ were mixed in amber bottles having $250 \mathrm{~mL}$ of a dye solution $(50 \mathrm{mg} / \mathrm{L})$ at $\mathrm{pH} \sim 7$. The same experimental procedure was followed for $\mathrm{pH}$ study. 
To obtain equilibrium conditions, the adsorption experiments were performed using four levels of concentration $\left(C_{i}=25,50,100\right.$, and $\left.150 \mathrm{mg} / \mathrm{L}\right)$ at optimum $\mathrm{pH}$. An amount of $0.5 \mathrm{~g}$ banana peel was added into each $250 \mathrm{~mL}$ dye solution at $25{ }^{\circ} \mathrm{C}$ and stirred in the magnetic stirrer for two hours. The samples were taken for spectrophotometric analysis in specific time intervals $(t=0,10,20,30,45,60,90$, and $120 \mathrm{~min})$. Equilibrium attained when the concentration of the final solution remained the same with increasing adsorption time. The adsorption efficiency (\% removal of dyes) and the adsorption capacity (amount adsorbed, $q$ ) were calculated using Equations (1) and (2), respectively [10]:

$$
\begin{gathered}
\text { Removal efficiency }(\%)=\frac{C_{i}-C_{f}}{C_{i}} \times 100 \\
\text { Adsorption capacity, } q(\mathrm{mg} / \mathrm{g})=\left(\frac{C_{i}-C_{f}}{M_{a d s}}\right) \times V
\end{gathered}
$$

where $C_{i}$ and $C_{f}$ denote the initial and final concentration $(\mathrm{mg} / \mathrm{L})$ of the dye solution respectively, $V$ is the solution volume (L), and $M_{a d s}$ is the weight of adsorbent used (g).

\subsubsection{Adsorption Isotherms}

The adsorption isotherm analysis provides an equilibrium relationship between adsorbate and adsorbent. The experimental adsorption data were fitted to Langmuir and Freundlich isotherms to obtain a suitable model to design a process for industrial wastewater treatment. The Langmuir isotherm model assumes monolayer adsorption of dyes at homogeneous adsorbent sites (identical and energetically indistinguishable) and that no transmigrations occur between adsorbed molecules on the neighboring sites. The linearized Langmuir isotherm model is expressed by Equation (3) [10]:

$$
\frac{C_{\mathrm{e}}}{q_{e}}=\frac{C_{\mathrm{e}}}{q_{m}}+\frac{1}{K_{L} q_{m}}
$$

where $q_{m}, q_{e}$ and $K_{L}$ denoted the maximum adsorption capacity (mg/g), adsorption capacity at equilibrium $(\mathrm{mg} / \mathrm{g})$ and Langmuir isotherm constant $(\mathrm{L} / \mathrm{mg})$, respectively. The values of $q_{m}$ and $K_{L}$ were estimated by plotting $C_{e} / q_{e}$ against $C_{e}$ where $q_{m}$ is the reciprocal of the slope and $K_{L}$ calculated from the intercept. The favorability of dye adsorption onto the banana peel was studied by a dimensionless separation factor $R_{L}$ obtained from the Langmuir isotherm model, which can be expressed as follows [29]:

$$
R_{L}=\frac{1}{1+K_{L} C_{i}}
$$

The isotherm model is favorable only when the value of $R_{L}$ remains in between 0 and 1 , it is unfavorable, linear, or irreversible if $R_{L}>1, R_{L}=1$, and $R_{L}=0$, respectively.

On the other hand, the Freundlich isotherm model postulates multilayer adsorption on heterogeneous adsorbent sites, where adsorbed molecules actively interact with each other. Equation (5) represents the linearized Freundlich isotherm model [10]:

$$
\ln \left(q_{e}\right)=\ln \left(K_{F}\right)+\frac{1}{n_{F}} \ln \left(C_{e}\right)
$$

where $1 / n_{F}$ and $K_{F}$ represent the heterogeneity factor associated with adsorption capacity, and the Freundlich isotherm constant $(\mathrm{mg} / \mathrm{g})$, respectively. Similar to the Langmuir isotherm, a linear line of $\ln \left(q_{e}\right)$ as a function of $\ln \left(C_{e}\right)$ was plotted to estimate the value of $K_{F}$ (from the intercept) and $n_{F}$ (from the slope). The value of $1 / n_{F}$ typically ranges from 0 to 1, illustrating the non-linearity of the relationship between dye solution concentration and adsorption. If $n_{F}=1$, the adsorption is linear otherwise it implies chemical $\left(1 / n_{F}<1\right)$ or physical $\left(1 / n_{F}>1\right)$ adsorption [10]. $1 / n_{F}<1$ also suggests the favorability of dye adsorption onto the adsorption surface [29]. 


\subsubsection{Adsorption Kinetics}

The adsorption kinetics study was done to understand the equilibrium relationships between adsorption and contact time. The experimental adsorption data were precisely fitted into the pseudo-first-order (PFO) and pseudo-second-order (PSO) kinetic models. The linearized equations for PFO and PSO are represented by Equations (6) and (7), respectively. In general, the rate of adoption in PFO is directly proportional to the first power of solution concentration, while the rate is related to the square of solution concentration for PSO [3]:

$$
\begin{gathered}
\ln \left(q_{e}-q_{t}\right)=\ln \left(q_{e}\right)-\frac{k_{1}}{2.303} t \\
\frac{t}{q_{t}}=\frac{1}{k_{2} q_{e}^{2}}+\frac{1}{q_{e}} t
\end{gathered}
$$

where $t$ is time $(\mathrm{min})$ and $q_{t}$ is adsorption capacity at instant time $(\mathrm{mg} / \mathrm{g})$. The rate constant for PFO and PSO adsorption was denoted by $k_{1}$ and $k_{2}$, respectively.

\subsubsection{Desorption Study}

The banana peel $(0.5 \mathrm{mg} / \mathrm{L})$ used for the adsorption of dye solution was separated using vacuum filtration. The exhausted adsorbent was treated individually or mutually under acidic and basic medium. Solutions $0.1 \mathrm{M} \mathrm{HCl}$ and $0.1 \mathrm{M} \mathrm{NaOH}$ were used to make acidic and basic environments, respectively. Prior to drying sample at $80^{\circ} \mathrm{C}$ for $12 \mathrm{~h}$, the adsorbent was washed with distilled water three times to remove residual acid or base solution from the adsorbent surface.

\section{Results and Discussion}

\subsection{FTIR Characterization}

The presence of important functional groups on the surface of banana peel was identified by the FTIR spectrum shown in Figure 3. The most intense and broadest peak at $3393.8 \mathrm{~cm}^{-1}$ indicates coinciding vibrations of $\mathrm{O}-\mathrm{H}$ (hydroxyl) stretching of alcohols and phenols and $\mathrm{N}-\mathrm{H}$ (amine) stretching of amino acid. Other strong peaks were also found in the range of 2850 to $3000 \mathrm{~cm}^{-1}$ that represent $\mathrm{C}-\mathrm{H}$ stretching of alkanes [30]. Peaks appearing at $1736.9,1620.2$, and $1399.4 \mathrm{~cm}^{-1}$ are designated to $\mathrm{C}=\mathrm{O}$ stretching of aldehydes or carboxylic acids, $-\mathrm{COO}$ symmetric stretching, and $\mathrm{O}-\mathrm{H}$ bending, respectively. The bands at $1000-1350 \mathrm{~cm}^{-1}$ and $650-1000 \mathrm{~cm}^{-1}$ are attributed to $C-O$ stretching of esters or ethers and $\mathrm{N}-\mathrm{H}$ deformation of amines, and $\mathrm{C}-\mathrm{H}$ stretching of alkenes and aromatics, respectively $[24,30]$. The FTIR spectra revealed that banana peel contained a high amount of hydroxyl and carboxylic groups, potentially from cellulose and amines from hemicellulose. These functional groups on adsorbent surface $\left(-\mathrm{COOH},-\mathrm{NH}_{2},-\mathrm{OH}\right.$, etc.) participate on hydrogen bonding via an electrostatic attractive force between $\mathrm{H}$-atoms in the functional groups of banana peel surface and more negatively charged atoms (e.g., N, O, etc.) on dye surface [23,31].

\subsection{Effects of Solution $p H$}

The $\mathrm{pH}$ is one of the most critical parameters primarily used to evaluate the adsorption capacity of banana peel to remove different reactive dyes from solution. The solution $\mathrm{pH}$ controls the adsorption capability as it has tremendous effects on the surface properties of the adsorbent and the forms (ionic or neutral) of dyes present in solution. A set of adsorption studies were performed in the $\mathrm{pH}$ range of 2-10 for $60 \mathrm{~min}$ at three different adsorption doses $(0.5,1.0$, and $2.0 \mathrm{~g} / \mathrm{L})$ while the initial dye concentration was held at $50 \mathrm{mg} / \mathrm{L}$. The uptake of dyes on the banana peel is exhibited against solution $\mathrm{pH}$ in Figure 4 . The percent removal of dyes increases with increasing $\mathrm{pH}$ and it suddenly goes to the highest $(93.4 \%, 97.1 \%$, and $99.6 \%$ for the adsorbent dose of $0.5,0.75$, and $1.0 \mathrm{~g}$, respectively) at $\mathrm{pH} \sim 7.0$. However, the adsorption falls when the $\mathrm{pH}$ is further increased. 
Analogous results were also attained in adsorption of dyes onto the banana peel [32], orange peel [32-34], shrimp shell [35], and biological waste slurry [36].

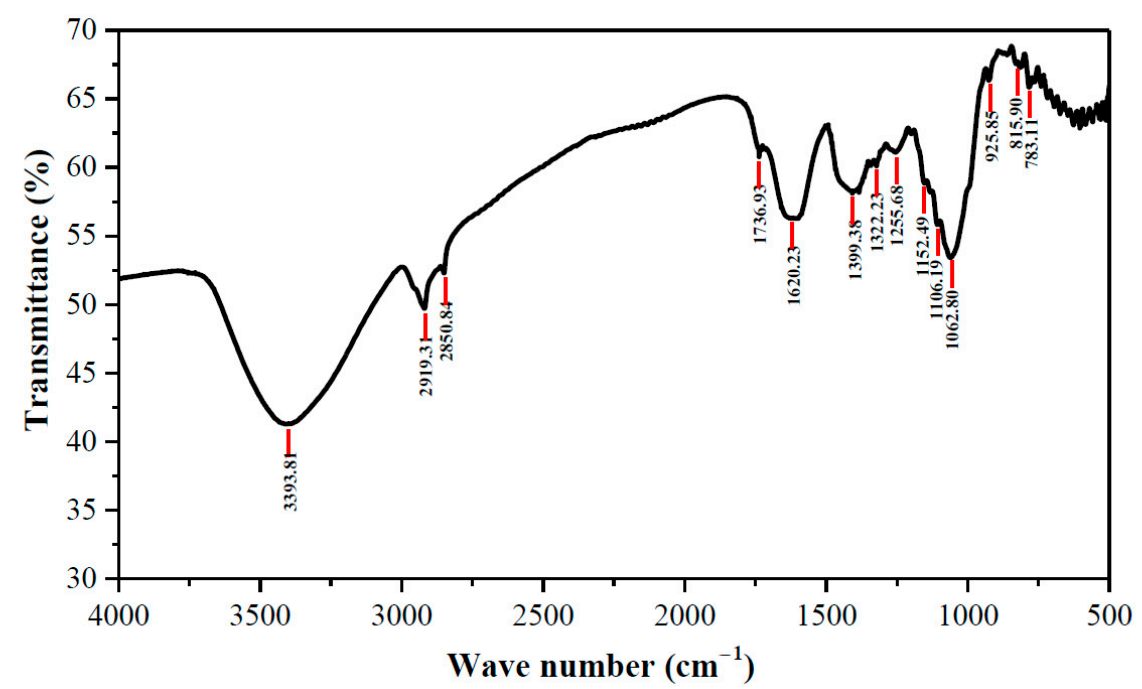

Figure 3. FTIR spectra of banana peel; Conditions: $25^{\circ} \mathrm{C}$, banana peel: $\mathrm{KBr}=1: 100$, number of scans: 30, resolution: $2 \mathrm{~cm}^{-1}$.

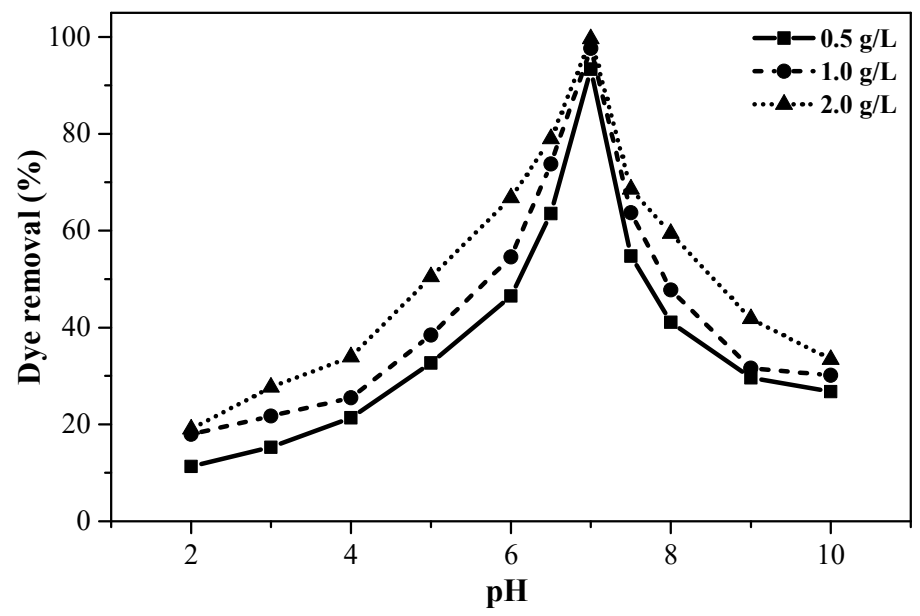

Figure 4. The adsorption of dyes on the banana peel at variable $\mathrm{pH}^{\prime} \mathrm{s}\left(C_{i}=50 \mathrm{mg} / \mathrm{L}, M_{a d s}=0.5,0.75\right.$, and $1.0 \mathrm{~g}, t=1 \mathrm{~h}, \mathrm{~T}=25^{\circ} \mathrm{C}, \mathrm{S}=180 \mathrm{rpm}, V=250 \mathrm{~mL}$ ).

The maximum adsorption at $\mathrm{pH}=7.0 \mathrm{implies}$ the presence of equal amounts of anions and cations in the dye solution which were simultaneously neutralized and adsorbed on the banana peel adsorption sites. Strong electrostatic interactions between charged molecules (e.g., $\mathrm{Na}^{+}, \mathrm{Cl}^{-}, \mathrm{SO}_{3} \mathrm{Na}^{+},-\mathrm{COO}^{-},-\mathrm{O}^{-}$, etc.) in dye solution and different functional groups such as $-\mathrm{COOH},-\mathrm{OH},-\mathrm{NH}_{2},-\mathrm{SO}_{4}$, etc in banana peel surface plays one of the major roles in the adsorption of dyes from the waste solution. The neutralization of dyes by $\mathrm{H}^{+}$ ions in acidic medium and $\mathrm{OH}^{-}$ions in basic medium might limit the removal of dyes with opposite ions from the solution. Therefore, the rest of the studies in this work was performed for a solution of $\mathrm{pH} \sim 7.0$.

\subsection{Effects of Adsorbent Dose}

The effects of adsorbent dosage on the removal of dyes are shown in Figure 5. About $20 \%$ of dyes were removed when $0.1 \mathrm{~g}$ banana peel was used, and almost complete removal $(\sim 94 \%)$ was observed for $0.5 \mathrm{~g}$ adsorbent. Little effect on the removal percentage is noticed for a further increase in the adsorbent dose ( $\sim 96 \%$ removal for $0.8 \mathrm{~g}$ dosage). Such a trend is understandable as the number of active sites is increased for the high dosage of banana peel 
while the amount of adsorbate molecules in the solution remains constant. Conversely, a drop of adsorption capacity from $28.4 \mathrm{mg} / \mathrm{g}$ (at $0.2 \mathrm{~g}$ dosage) to $14.9 \mathrm{mg} / \mathrm{g}$ (at $0.8 \mathrm{~g}$ dosage) was observed after an initial increase. At dosages $<0.2 \mathrm{~g}$, the active sites of banana peel may saturate quickly and this left a significant amount of dyes in the solution, leading to an increase in adsorption capacity with increased dosage (up to $0.2 \mathrm{~g}$ ) [6]. Besides, the decrease in adsorption capacity at higher dosages may be attributed to two reasons. Firstly, the unsaturation of active adsorption sites of banana peel occurred at higher dosages, due to the presence of excess adsorbent than necessary while the adsorption capacity is inversely related to the amount of adsorbent dosage. Secondly, the aggregation of adsorbent particles due to the high addition of adsorbent dosage caused a significant drop in surface area and an increase in diffusional path length [37], leading to limiting the adsorption process.

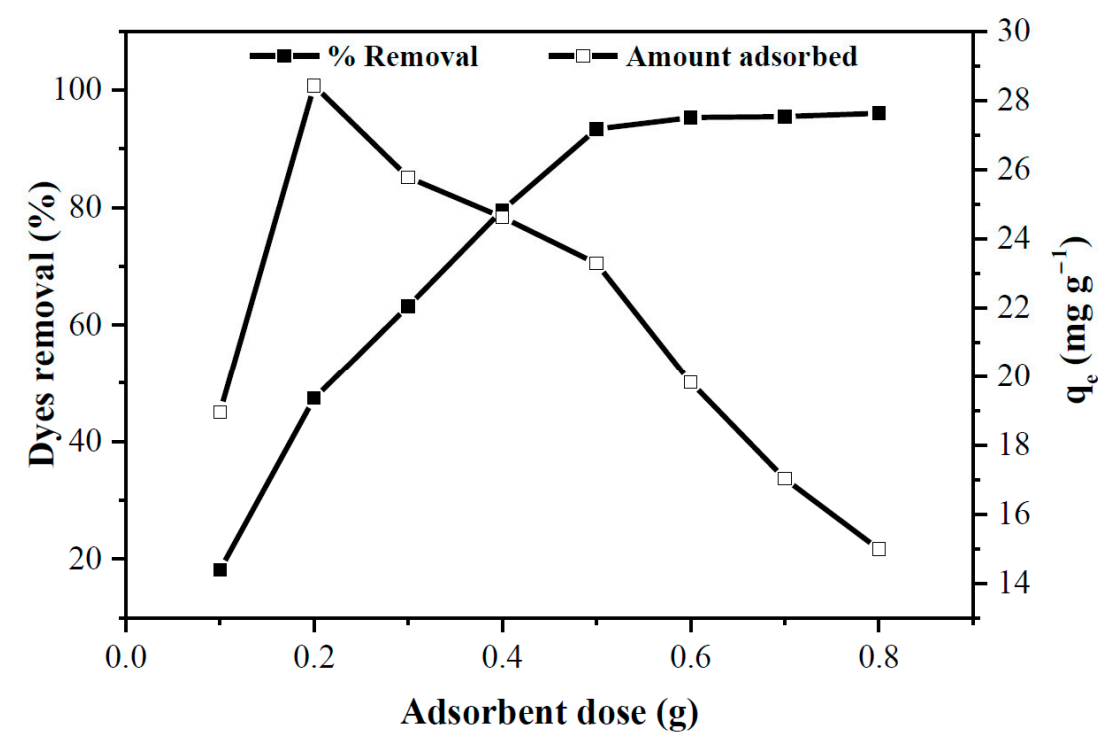

Figure 5. Effects of adsorbent dosage on the dye adsorption onto the banana peel $(\mathrm{pH}=7$, $C_{i}: 50 \mathrm{mg} / \mathrm{L}, M_{a d s}: 0.1$ to $0.8 \mathrm{~g}, t: 1 \mathrm{~h}, \mathrm{~T}: 25^{\circ} \mathrm{C}, \mathrm{S}: 180 \mathrm{rpm}$, solution volume: $250 \mathrm{~mL}$ ).

\subsection{Effects of Initial Concentration and Contact Time}

The effects of initial dye concentration and contact time were simultaneously studied in this work. The dye removal efficiency and adsorption capacity are demonstrated as a function of time with four levels of dye concentration $\left(C_{i}=25,50,100\right.$, and $\left.150 \mathrm{mg} / \mathrm{L}\right)$ in Figure $6 \mathrm{a}, \mathrm{b}$ respectively. The analogous trends of percent dye removal in Figure 6a show that the first $10 \mathrm{~min}$ of adsorption was very quick which then proceeded slow down until a plateau state was reached. For all initial concentrations, the equilibrium was attained within $60 \mathrm{~min}$ of the adsorption process, except for $150 \mathrm{mg} / \mathrm{L}$ solution, which plateaued in about $90 \mathrm{~min}$. The abundant availability of active adsorption sites at the initial stage causes high interactions between adsorbent and dyes, resulting in rapid adsorption. Decreasing active sites over time because of the adoption process leads to a gradual decrease in the rate of adsorption, which continues until the dynamic equilibrium between the adsorption and desorption of dyes is achieved. The slower adsorption at high concentration solutions was attributed to the presence of relatively lower number of active sites to remove the same amount of dyes as the solution volume and adsorbent quantity in the system remained constant. In addition to that, the existence of such inadequacy of active sites at higher concentration solutions also offered considerably lower dye removal efficiency. Only $43.4 \%$ of dyes were removed at $C_{i}=150 \mathrm{mg} / \mathrm{L}$ while the removal efficiencies were $56 \%, 96.2 \%$, and $100 \%$ for 100,50 , and $25 \mathrm{mg} / \mathrm{L}$ solution, respectively. Similar results were also obtained by Arami et al. [9]. 

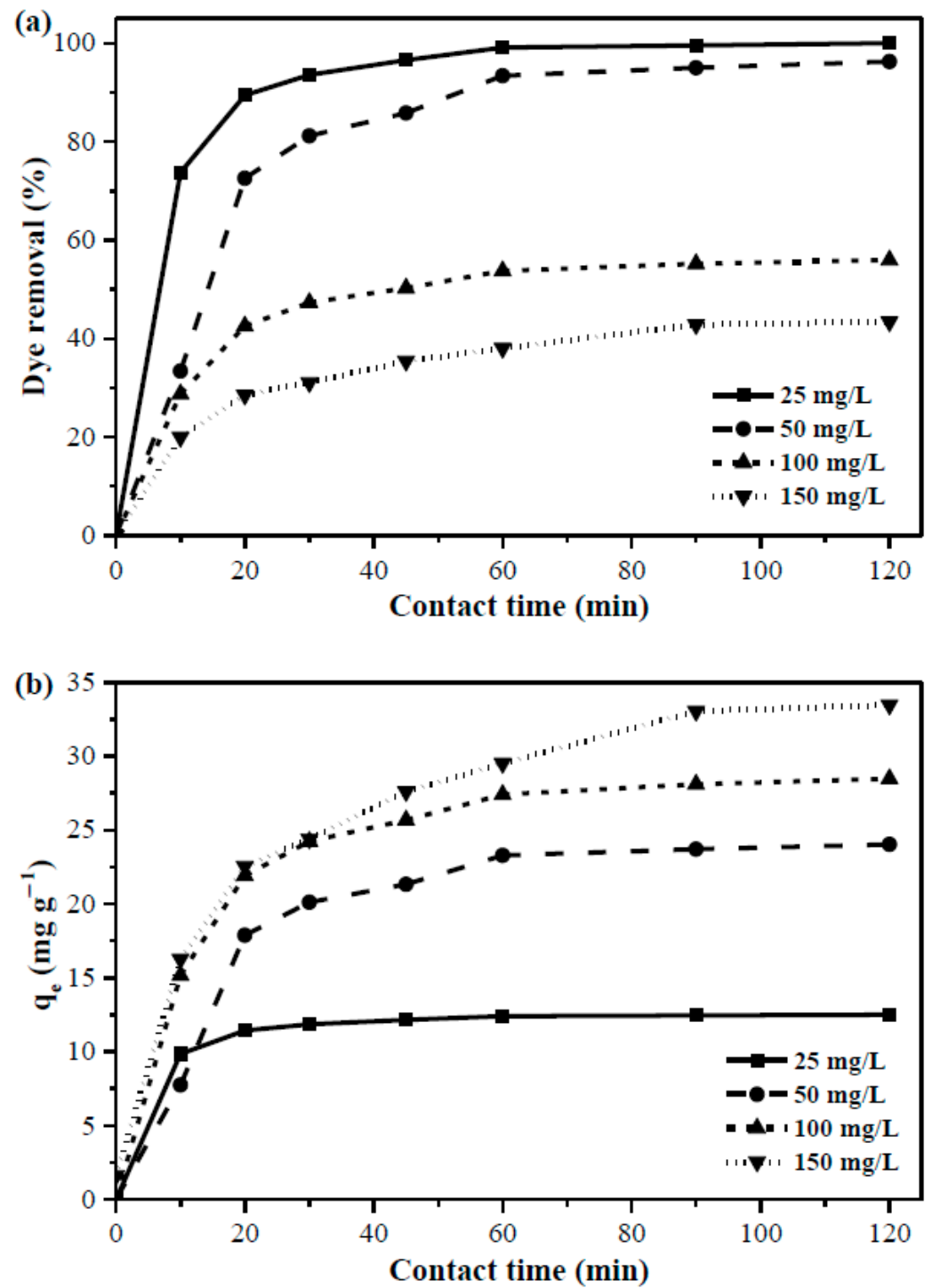

Figure 6. (a) The percent removal of dyes and (b) amount of dyes adsorbed for variable contact time and initial concentration ( $\mathrm{pH}: 7, \mathrm{C}_{i}: 25,50,100$, and $150 \mathrm{mg} / \mathrm{L}, M_{a d s}: 0.5 \mathrm{~g}, t: 0$ to $120 \mathrm{~min}, \mathrm{~T}: 25^{\circ} \mathrm{C}$, S: $180 \mathrm{rpm}$, solution volume: $250 \mathrm{~mL})$.

Conversely, the adsorption capacity of banana peel was higher for the dye-rich solutions (i.e., $33.5 \mathrm{mg} / \mathrm{g}$ at $150 \mathrm{mg} / \mathrm{L}$ and $12.5 \mathrm{mg} / \mathrm{g}$ at $25 \mathrm{mg} / \mathrm{L}$ ) as the number of dye molecules in the constant volume and adsorbent mass is increased at high dye concentration solution, resulting in high quantity dye adsorption. However, the trend of adsorption capacities of banana peel in Figure $6 \mathrm{~b}$ always corresponded to the trend of dye removal efficiency shown in Figure 6a.

\subsection{Adsorption Isotherms}

Adsorption isotherm studies were conducted in the concentration range $25-200 \mathrm{mg} / \mathrm{L}$ under the following conditions: $0.5 \mathrm{~g}$ banana peel, $\mathrm{pH} \sim 7$, and $25^{\circ} \mathrm{C}$. The adsorbateadsorbent mixing was done in the magnetic stirrer for $1 \mathrm{~h}$ with a rotational speed of $180 \mathrm{rpm}$. The same procedure as the adsorption study (Section 2.5) was used to obtain equilibrium concentrations, percent dye removal, and the amount of dye adsorbed. Fitting experimental data to isotherm equations (Equations (3) and (5)) suggest that the Langmuir isotherm model (Figure 7a) shows a relatively better fit to the adsorption data, which revealed by higher $\mathrm{R}^{2}$ value compared to the Freundlich model (Figure $7 \mathrm{~b}$ ). The adsorption parameters with corresponding $R^{2}$ value for both isotherm model are summarized in Table 1. 

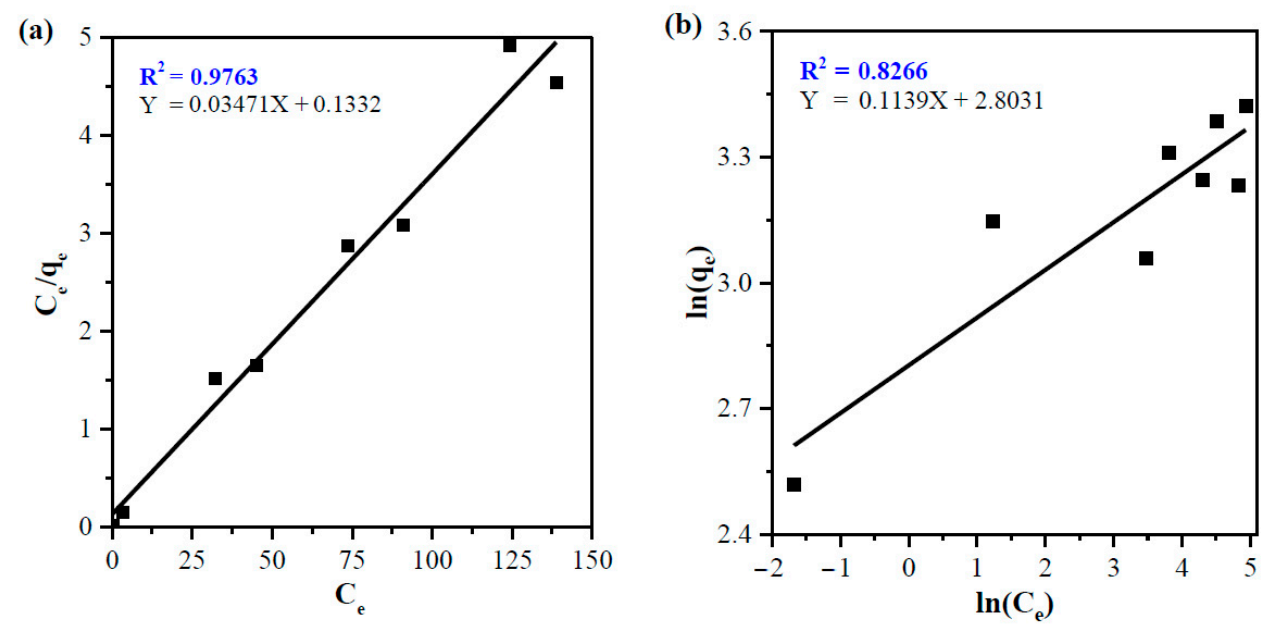

Figure 7. (a) Langmuir and (b) Freundlich isotherm model plots for adsorption of dyes onto the banana peel (pH: 7, $C_{i}: 25,50,75,100,150$ and $200 \mathrm{mg} / \mathrm{L}, M_{a d s}: 0.5 \mathrm{~g}, t: 60 \mathrm{~min}, \mathrm{~T}: 25^{\circ} \mathrm{C}, \mathrm{S}: 180 \mathrm{rpm}$, solution volume: $250 \mathrm{~mL}$ ).

Table 1. Adsorption isotherm parameters for dye adsorption onto the banana peel.

\begin{tabular}{ccccccc}
\hline \multicolumn{3}{c}{ Langmuir } & \multicolumn{3}{c}{ Freundlich } \\
\hline $\boldsymbol{q}_{\boldsymbol{m}}(\mathbf{m g} / \mathbf{g})$ & $\boldsymbol{K}_{\boldsymbol{L}}(\mathbf{L} / \mathbf{m g})$ & $\mathbf{R}^{\mathbf{2}}$ & $\boldsymbol{R}_{\boldsymbol{L}}$ & $\mathbf{1} / \boldsymbol{n}_{\boldsymbol{F}}$ & $\boldsymbol{K}_{\boldsymbol{F}}(\mathbf{m g} \mathbf{g})$ & $\mathbf{R}^{\mathbf{2}}$ \\
\hline 28.8 & 0.26 & 0.9763 & $0.02-0.14$ & 0.114 & 16.5 & 0.8266 \\
\hline
\end{tabular}

The better fitting of experimental data to the Langmuir isotherm model indicates the occurrence of monolayer adsorption at specific homogeneous adsorption sites of the banana peel. The lower $R^{2}$ value in the Freundlich model was obtained owing to the non-linear adsorption behavior $(1 / n F \sim 0.114<1)$, especially at high concentrations, which is caused by saturation of adsorbent actives sites on the surface.

To describe the favorability of dye adsorption onto the banana peel by the Langmuir isotherm model, $R_{L}$ was plotted as a function of $C_{i}$, which is shown in Figure 8. The highest value of $R_{L}$ (0.133) was obtained at $25 \mathrm{mg} / \mathrm{L}$ that decreased to 0.02 at $200 \mathrm{mg} / \mathrm{L}$. However, the values of $R_{L}$ were always found in the range of 0.02-0.14 $(<<1)$, indicating the favorable dye adsorption on a banana peel. Like the Langmuir isotherm model, the Freundlich isotherm model also shows the favorable dye adsorption, which was confirmed by obtaining the value of $1 / n_{F}$ less than unity (Table 1 ).

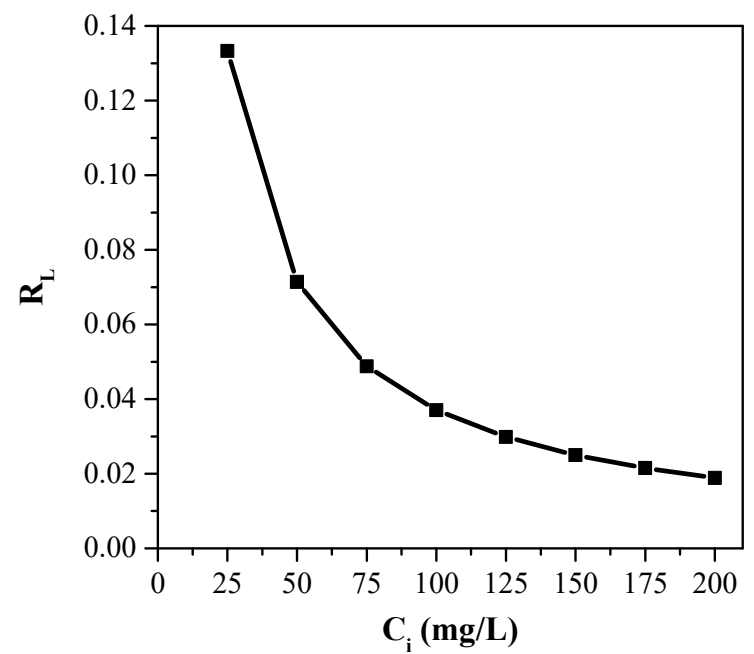

Figure 8. Graphical presentation of the separation factor $\left(\mathrm{R}_{\mathrm{L}}\right)$ against initial dye concentration ( $\mathrm{pH}$ : 7, $C_{i}: 25,50,75,100,150$ and $200 \mathrm{mg} / \mathrm{L}, M_{a d s}: 0.5 \mathrm{~g}$, $t: 60 \mathrm{~min}, \mathrm{~T}: 25^{\circ} \mathrm{C}, \mathrm{S}: 180 \mathrm{rpm}$, solution volume: $\left.250 \mathrm{~mL}\right)$. 


\subsection{Adsorption Kinetics}

In kinetic studies, the adsorption capacity of banana peel at equilibrium was examined for times ranging from 0 to $120 \mathrm{~min}$ using three dye concentration levels $(25,50$, and $100 \mathrm{mg} / \mathrm{L}$ ) under the following conditions: $0.5 \mathrm{~g}$ banana peel, $\mathrm{pH} \sim 7$, and $25{ }^{\circ} \mathrm{C}$ and maintained identical procedure as adsorption study (Section 2.5) to attain equilibrium concentration and adsorption capacity. The adsorption kinetic at different dye concentrations were evaluated by fitting experimental adsorption data into the linearized PFO and PSO model equations, which are shown in Figure 9. The higher $R^{2}$ value in Figure 9 reveals a better fit of experimental data to the PSO compared to PFO, suggesting a chemisorptioncontrolled adsorption process [3,38], which is also validated by isotherm studies (reported in Section 3.5) since $1 / n_{F}$ is less than unity. The rate constant $\left(k_{1}\right.$ and $\left.k_{2}\right)$ and theoretical adsorption capacity at equilibrium $\left(q_{e, \text { calc }}\right)$ along with the $\mathrm{R}^{2}$ values for both kinetic models are listed in Table 2.
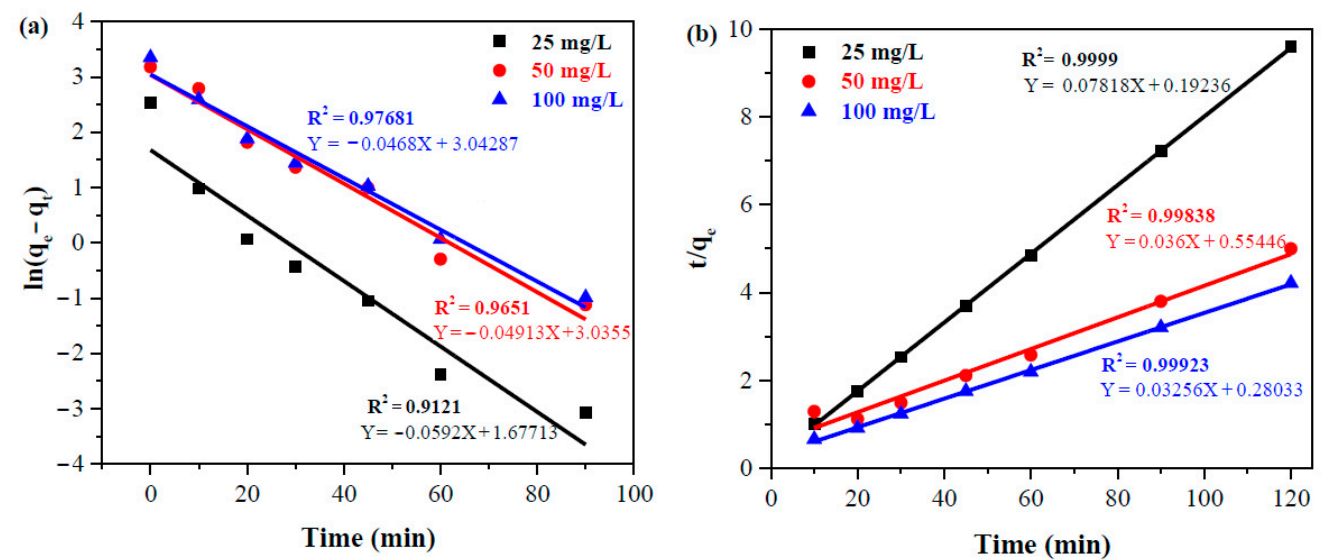

Figure 9. (a) Pseudo-first-order and (b) pseudo-second-order kinetics for the adsorption of dyes onto the banana peel.

Table 2. Adsorption kinetic parameters for dye adsorption onto the banana peel.

\begin{tabular}{ccccc}
\hline \multirow{2}{*}{ Kinetic Model } & \multirow{2}{*}{ Parameter } & \multicolumn{2}{c}{ Initial Dye Concentration $(\mathbf{m g} / \mathrm{L})$} \\
\cline { 3 - 5 } & & $\mathbf{2 5}$ & $\mathbf{5 0}$ & $\mathbf{1 0 0}$ \\
\hline \multirow{3}{*}{ Pseudo-first-order } & $\mathrm{R}^{2}$ & 0.9121 & 0.9651 & 0.9768 \\
& $k_{1}\left(\mathrm{~min}^{-1}\right)$ & 0.059 & 0.049 & 0.047 \\
& $q_{e, \text { calc }}(\mathrm{mg} / \mathrm{g})$ & 5.4 & 20.8 & 21.0 \\
\hline \multirow{3}{*}{ Pseudo-second-order } & $\mathrm{R}^{2}$ & 0.9999 & 0.9984 & 0.9992 \\
& $k_{2}\left(\mathrm{~g} \mathrm{mg}^{-1} \mathrm{~min}^{-1}\right)$ & 0.032 & 0.036 & 0.033 \\
& $q_{e, \text { calc }}(\mathrm{mg} / \mathrm{g})$ & 12.8 & 27.8 & 30.7 \\
& $q_{e, \text { exp }}(\mathrm{mg} / \mathrm{g})$ & 12.5 & 24.0 & 28.4 \\
\hline
\end{tabular}

\subsection{Adsorption Study on Textile Wastewater}

The optimized parameters, including solution $\mathrm{pH}$, adsorbent dose, and contact time, found for the standard solution were implemented to treat actual collected textile wastewater. Since the concentration was unknown, the wastewater was diluted until an initial absorbance of about 0.612 , which corresponds to $56 \mathrm{mg} / \mathrm{L}$ (obtained using calibration curve). A mixture of $0.5 \mathrm{~g}$ banana peel and $250 \mathrm{~mL}$ wastewater $(56 \mathrm{mg} / \mathrm{L})$ was stirred on a magnetic stirrer at $\mathrm{pH} \sim 7$ for an hour with $\mathrm{S}=180 \mathrm{rpm}$. The final concentration found after the adsorption was $8.2 \mathrm{mg} / \mathrm{L}$ (absorbance $=0.088$ ), indicating $84.2 \%$ of dye removal that is about $9 \%$ lower from the value obtained for the standard solution of $50 \mathrm{mg} / \mathrm{L}$. This slightly lower adsorption capacity in dye removal from wastewater may occur due to (1) a small increase in initial dye concentration as the percent dye removal decreases with initial dye concentration (2) the difference of dye composition in wastewater and the standard 
solution, which can affect the calibration curve, and (3) the presence of dyeing auxiliaries (salts, alkalies, surfactants and softeners) in industrial wastewater (that was not accounted for in the experiments with standard dye solution) might have a negative impact on the adsorption capacity. The adsorption capacities of different forms of banana peel along with other bio-adsorbents to remove dyes have been summarized in Table 3.

Table 3. Adsorption Capacities of banana waste-based adsorbent for the removal of dyes.

\begin{tabular}{|c|c|c|c|c|c|c|c|}
\hline Adsorbent & Adsorbate & $q_{m}(\mathrm{mg} / \mathrm{g})$ & Conc. (mg/L) & Contact Time & $\mathrm{pH}$ & \% Removal & Ref. \\
\hline Banana peel & Methylene blue & 18.647 & $5-100$ & $3 \mathrm{~h}$ & $4-8$ & $96-98$ & \\
\hline Activated banana peel & Methylene blue & 19.671 & $5-100$ & $3 \mathrm{~h}$ & $4-8$ & $90-94$ & [39] \\
\hline Pseudo stream banana fiber & Safanin & 21.74 & $5-40$ & $90 \mathrm{~min}$ & 7.5 & - & {$[40]$} \\
\hline Banana pith & Methylene blue & 11.325 & $5-25$ & $3 \mathrm{~h}$ & & 89 & [41] \\
\hline Banana peel AC & Methylene blue & 620 & 1000 & $24 \mathrm{~h}$ & 8.0 & & [42] \\
\hline Banana peel powder & Eurozol Navy blue & 24.09 & 50 & $60 \mathrm{~min}$ & 7.0 & $68-72$ & [43] \\
\hline Chitosan/Banana peel & Methylene blue & - & & $100 \mathrm{~min}$ & 7.0 & 96 & [44] \\
\hline
\end{tabular}

\subsection{Adsorbent Regeneration Study}

Regeneration of adsorbent helps explain the mechanism and recovery of the adsorbate and adsorbent. Figure 10 illustrates the \%desorption of dyes in different solvent media. Initially, $0.1 \mathrm{M} \mathrm{HCl}(\mathrm{A})$ and $0.1 \mathrm{M} \mathrm{NaOH}$ (B) solutions were used to desorb dyes from the adsorbent surface. In both cases, \% recoveries were similar $(51.2 \pm 3.2 \%$ with $\mathrm{HCl}$ and $47.9 \pm 4.6 \%$ with $\mathrm{NaOH}$ solution). However, when the adsorbent was treated subsequently with $0.1 \mathrm{M} \mathrm{HCl}$ and $0.1 \mathrm{M} \mathrm{NaOH}(\mathrm{C})$, the regeneration of adsorbent surface was about $94.5 \pm 5.1 \%$ which was approximately double than seen with the individual acid or base treatments. As mentioned in the adsorption study, the dye solution contained the same amount of positive and negative functional groups and the maximum adsorption was obtained at $\mathrm{pH}=7.0$, which indicates that both basic and acidic media are required to create extreme conditions and eventually desorb dyes from the adsorbent surface. In acidic medium, the solution consists of a higher amount of $\mathrm{H}^{+}$that subsequently attach with the dye molecules with negative functional groups and are desorbed from the adsorbent surface. Similarly, in basic medium, the dye molecules containing positive functional groups were removed. Therefore, when treated with acid and base one after another, a very high \%recovery is achieved. Here, \%recovery of this acid-base treatment is $4.6 \%$ less than the combination (99.1\%) of individual acid and base treatments because of the neutralization reaction between residual $\mathrm{HCl}$ and $\mathrm{NaOH}$ solutions.

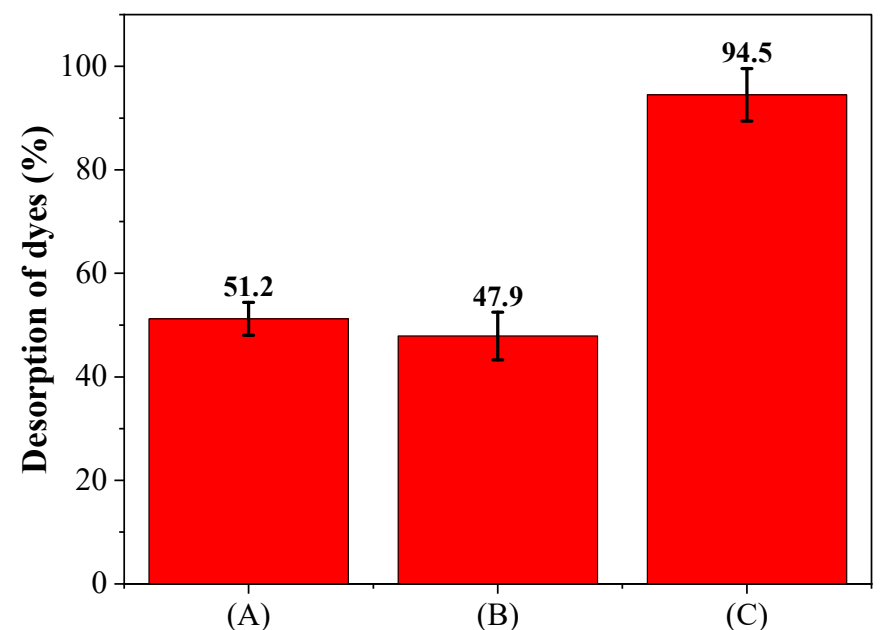

Solvents

Figure 10. Regeneration of banana peel using different solvents: (A) $0.1 \mathrm{M} \mathrm{HCl}$, (B) $0.1 \mathrm{M} \mathrm{NaOH}$, and (C) subsequent addition of $0.1 \mathrm{M} \mathrm{HCl}$ and $0.1 \mathrm{M} \mathrm{NaOH}$. 


\section{Conclusions}

In summary, banana peel has shown tremendous adsorption capacity for the removal of dyes from textile effluents. Prior to treating actual wastewater, a set of parameters were optimized using the standard solution containing a mixture of three major dyes present in the wastewater. The FTIR study revealed that banana peel contained a high amount of hydroxyl, amine and carboxylic groups on the surface that cause high interactions between adsorbate and adsorbent, resulting in high dye removal efficiency and adsorption capacity. The optimum adsorption at $\mathrm{pH} \sim 7$ indicates the presence of equal amounts of anions and cations in the wastewater solution. Although the adsorption capacity was further increased with adsorbent dose, it was minimal for adsorbent doses above $0.5 \mathrm{~g}$. The equilibrium was reached within $60 \mathrm{~min}$ of adsorption; however, it was a little longer for solution concentration above $100 \mathrm{mg} / \mathrm{L}$ due to insufficient adsorption sites. A Langmuir isotherm model and a pseudo-second-order kinetic model fitted the experimental adsorption data well, which suggested that the dye removal using banana peel is a favorable chemisorption process. This study shows that low-cost and renewable biowaste-derived banana peel has high adsorption performance towards textile dyes. Additionally, about $95 \%$ of the banana peel is recoverable with subsequent acid and base treatments and can can be re-used for further dye adsorption.

Author Contributions: Conceptualization, M.Z.A., F.B.A.R. and M.A.; methodology, M.A.; software, F.B.A.R. and S.M.F.K.; validation, M.A., S.M.F.K. and M.Z.A.; formal analysis, F.B.A.R.; investigation, M.A. and F.B.A.R.; resources, M.A.; data curation, S.M.F.K. and F.B.A.R.; writing-original draft preparation, M.A. and F.B.A.R.; writing-review and editing, F.B.A.R., M.A. and S.M.F.K.; visualization, F.B.A.R.; supervision, M.Z.A.; project administration, M.Z.A.; funding acquisition, M.Z.A. All authors have read and agreed to the published version of the manuscript.

Funding: This research received no external funding.

Institutional Review Board Statement: Not applicable.

Informed Consent Statement: Not applicable.

Data Availability Statement: The data presented in this study are available within the manuscript.

Conflicts of Interest: The authors declare no conflict of interest.

\section{References}

1. Leal, T.W.; Lourenco, L.A.; Scheibe, A.S.; de Souza, S.M.G.U.; de Souza, A.A.U. Textile wastewater treatment using low-cost adsorbent aiming the water reuse in dyeing process. J. Environ. Chem. Eng. 2018, 6, 2705-2712. [CrossRef]

2. Nuithitikul, K.; Srikhun, S.; Hirunpraditkoon, S. Kinetics and equilibrium adsorption of Basic Green 4 dye on activated carbon derived from durian peel: Effects of pyrolysis and post-treatment conditions. J. Taiwan Inst. Chem. Eng. 2010, 41, 591-598. [CrossRef]

3. Wong, S.; Abd Ghafar, N.; Ngadi, N.; Razmi, F.A.; Inuwa, I.M.; Mat, R.; Amin, N.A.S. Effective removal of anionic textile dyes using adsorbent synthesized from coffee waste. Sci. Rep. 2020, 10, 1-13. [CrossRef]

4. Pirkarami, A.; Olya, M.E. Removal of dye from industrial wastewater with an emphasis on improving economic efficiency and degradation mechanism. J. Saudi Chem. Soc. 2017, 21, S179-S186. [CrossRef]

5. Yagub, M.T.; Sen, T.K.; Afroze, S.; Ang, H.M. Dye and its removal from aqueous solution by adsorption: A review. Adv. Colloid Interface Sci. 2014, 209, 172-184. [CrossRef]

6. Kabir, S.; Cueto, R.; Balamurugan, S.; Romeo, L.D.; Kuttruff, J.T.; Marx, B.D.; Negulescu, I.I. Removal of acid dyes from textile wastewaters using fish scales by absorption process. Clean Technol. 2019, 1, 311-324. [CrossRef]

7. Kabir, S. Waste Management by Waste: Removal of Acid Dyes from Wastewaters of Textile Coloration Using Fish Scales. Master's Thesis, Louisiana State University, Baton Rouge, LA, USA, 2018.

8. Naushad, M.; Ahamad, T.; Alothman, Z.A.; Ala'a, H. Green and eco-friendly nanocomposite for the removal of toxic $\mathrm{Hg}$ (II) metal ion from aqueous environment: Adsorption kinetics \& isotherm modelling. J. Mol. Liq. 2019, 279, 1-8.

9. Arami, M.; Limaee, N.Y.; Mahmoodi, N.M.; Tabrizi, N.S. Removal of dyes from colored textile wastewater by orange peel adsorbent: Equilibrium and kinetic studies. J. Colloid Interface Sci. 2005, 288, 371-376. [CrossRef]

10. Gimbert, F.; Morin-Crini, N.; Renault, F.; Badot, P.-M.; Crini, G. Adsorption isotherm models for dye removal by cationized starch-based material in a single component system: Error analysis. J. Hazard. Mater. 2008, 157, 34-46. [CrossRef] [PubMed] 
11. Wong, S.; Lim, Y.; Ngadi, N.; Mat, R.; Hassan, O.; Inuwa, I.M.; Mohamed, N.B.; Low, J.H. Removal of acetaminophen by activated carbon synthesized from spent tea leaves: Equilibrium, kinetics and thermodynamics studies. Powder Technol. 2018, 338, 878-886. [CrossRef]

12. Li, W.; Mu, B.; Yang, Y. Feasibility of industrial-scale treatment of dye wastewater via bio-adsorption technology. Bioresour. Technol. 2019, 277, 157-170. [CrossRef]

13. Biswas, S.; Rashid, T.U.; Debnath, T.; Haque, P.; Rahman, M.M. Application of chitosan-clay biocomposite beads for removal of heavy metal and dye from industrial effluent. J. Compos. Sci. 2020, 4, 16. [CrossRef]

14. Kabir, S.; Rashid, T.U.; Negulescu, I.I. Gelation of textile dye solution treated with fish scales. Gels 2019, 5, 37. [CrossRef] [PubMed]

15. Naushad, M.; Mittal, A.; Rathore, M.; Gupta, V. Ion-exchange kinetic studies for Cd(II), Co(II), Cu(II), and Pb(II) metal ions over a composite cation exchanger. Desalination Water Treat. 2015, 54, 2883-2890. [CrossRef]

16. Munagapati, V.S.; Wen, J.-C.; Pan, C.-L.; Gutha, Y.; Wen, J.-H.; Reddy, G.M. Adsorptive removal of anionic dye (Reactive Black 5) from aqueous solution using chemically modified banana peel powder: Kinetic, isotherm, thermodynamic, and reusability studies. Int. J. Phytoremediation 2020, 22, 267-278. [CrossRef]

17. Vilardi, G.; Di Palma, L.; Verdone, N. Heavy metals adsorption by banana peels micro-powder: Equilibrium modeling by non-linear models. Chin. J. Chem. Eng. 2018, 26, 455-464. [CrossRef]

18. Silva, C.R.; Gomes, T.F.; Andrade, G.C.; Monteiro, S.H.; Dias, A.C.; Zagatto, E.A.; Tornisielo, V.L. Banana peel as an adsorbent for removing atrazine and ametryne from waters. J. Agric. Food Chem. 2013, 61, 2358-2363. [CrossRef] [PubMed]

19. Oyewo, O.A.; Onyango, M.S.; Wolkersdorfer, C. Application of banana peels nanosorbent for the removal of radioactive minerals from real mine water. J. Environ. Radioact. 2016, 164, 369-376. [CrossRef]

20. Achak, M.; Hafidi, A.; Ouazzani, N.; Sayadi, S.; Mandi, L. Low cost biosorbent "banana peel" for the removal of phenolic compounds from olive mill wastewater: Kinetic and equilibrium studies. J. Hazard. Mater. 2009, 166, 117-125. [CrossRef] [PubMed]

21. Kamar, F.H.; Niamat, F.E.; Faisal, A.A.; Mohammed, A.A.; Nechifor, A.C.; Nechifor, G. Use of artificial neural network for modeling and prediction of reactive red dye removal from wastewater using banana peels bio-sorbent. Rev. De Chim. 2018, 69, 1919-1926. [CrossRef]

22. Mondal, N.K.; Kar, S. Potentiality of banana peel for removal of Congo red dye from aqueous solution: Isotherm, kinetics and thermodynamics studies. Appl. Water Sci. 2018, 8, 157. [CrossRef]

23. Oyekanmi, A.A.; Ahmad, A.; Hossain, K.; Rafatullah, M. Adsorption of Rhodamine B dye from aqueous solution onto acid treated banana peel: Response surface methodology, kinetics and isotherm studies. PLoS ONE 2019, 14, e0216878. [CrossRef]

24. Memon, J.R.; Memon, S.Q.; Bhanger, M.; Memon, G.Z.; El-Turki, A.; Allen, G.C. Characterization of banana peel by scanning electron microscopy and FT-IR spectroscopy and its use for cadmium removal. Colloids Surf. B Biointerfaces 2008, 66, 260-265. [CrossRef]

25. Munagapati, V.S.; Yarramuthi, V.; Kim, Y.; Lee, K.M.; Kim, D.-S. Removal of anionic dyes (Reactive Black 5 and Congo Red) from aqueous solutions using Banana Peel Powder as an adsorbent. Ecotoxicol. Environ. Saf. 2018, 148, 601-607. [CrossRef]

26. Palma, C.; Contreras, E.; Urra, J.; Martínez, M.J. Eco-friendly technologies based on banana peel use for the decolourization of the dyeing process wastewater. Waste Biomass Valorization 2011, 2, 77-86. [CrossRef]

27. Hashem, A.H.; Saied, E.; Hasanin, M.S. Green and ecofriendly bio-removal of methylene blue dye from aqueous solution using biologically activated banana peel waste. Sustain. Chem. Pharm. 2020, 18, 100333. [CrossRef]

28. Ma, J.; Huang, D.; Zou, J.; Li, L.; Kong, Y.; Komarneni, S. Adsorption of methylene blue and Orange II pollutants on activated carbon prepared from banana peel. J. Porous Mater. 2015, 22, 301-311. [CrossRef]

29. Unuabonah, E.I.; Adie, G.U.; Onah, L.O.; Adeyemi, O.G. Multistage optimization of the adsorption of methylene blue dye onto defatted Carica papaya seeds. Chem. Eng. J. 2009, 155, 567-579. [CrossRef]

30. Pavia, D.L.; Lampman, G.M.; Kriz, G.S.; Vyvyan, J.A. Introduction to Spectroscopy; Cengage learning: Boston, MA, USA, 2014.

31. Laskar, N.; Kumar, U. SEM, FTIR and EDAX studies for the removal of safranin dye from water bodies using modified biomaterial-Bambusa tulda. In Proceedings of the IOP Conference Series: Materials Science and Engineering, Busan, Korea, 25-27 August 2017; p. 012105.

32. Annadurai, G.; Juang, R.-S.; Lee, D.-J. Use of cellulose-based wastes for adsorption of dyes from aqueous solutions. J. Hazard. Mater. 2002, 92, 263-274. [CrossRef]

33. AbdurRahman, F.B.; Akter, M.; Abedin, M.Z. Dyes removal from textile wastewater using orange peels. Int. J. Sci. Technol. Res. 2013, 2, 47-50.

34. Namasivayam, C.; Muniasamy, N.; Gayatri, K.; Rani, M.; Ranganathan, K. Removal of dyes from aqueous solutions by cellulosic waste orange peel. Bioresour. Technol. 1996, 57, 37-43. [CrossRef]

35. Rahman, F.; Akter, M. Removal of dyes form textile wastewater by adsorption using shrimp shell. Int. J. Waste Resour $2016,6,2$.

36. Yamuna, R.; Namasivayam, C. Color removal from aqueous solution by biogas residual slurry. Toxicol. Environ. Chem. 1993, 38, 131-143. [CrossRef]

37. El Qada, E.N.; Allen, S.J.; Walker, G.M. Adsorption of basic dyes onto activated carbon using microcolumns. Ind. Eng. Chem. Res. 2006, 45, 6044-6049. [CrossRef] 
38. Li, H.; Cao, X.; Zhang, C.; Yu, Q.; Zhao, Z.; Niu, X.; Sun, X.; Liu, Y.; Ma, L.; Li, Z. Enhanced adsorptive removal of anionic and cationic dyes from single or mixed dye solutions using MOF PCN-222. RSC Adv. 2017, 7, 16273-16281. [CrossRef]

39. Amela, K.; Hassen, M.A.; Kerroum, D. Isotherm and kinetics study of biosorption of cationic dye onto banana peel. Energy Procedia 2012, 19, 286-295. [CrossRef]

40. de Sousa, A.É.A.; Gomes, E.C.C.; de Quadros Melo, D.; Diógenes, I.C.N.; Becker, H.; Longhinotti, E. Adsorption of safranin on pseudostem banana fibers. Sep. Sci. Technol. 2014, 49, 2681-2688. [CrossRef]

41. El-Maghraby, A.; Taha, N.A. Equilibrium and kinetic studies for the removal of cationic dye using banana pith. Adv. Environ. Res. Int. J. 2014, 3, 217-230. [CrossRef]

42. Hashem, F.; Amin, M. Adsorption of methylene blue by activated carbon derived from various fruit peels. Desalination Water Treat. 2016, 57, 22573-22584. [CrossRef]

43. Ahmed, A.E.; Majewska-Nowak, K. Removal of Reactive Dye from Aqueous Solutions Using Banana Peel and Sugarcane Bagasse as Biosorbents. Environ. Prot. Eng. 2020, 46, 121-135. [CrossRef]

44. Djilani, C.; Zaghdoudi, R.; Magri, P.; Djazi, F.; Lallam, A.; Bouchekima, B. Elaboration and characterization of chitosan/banana peel biocomposite for the removal of dyes from wastewater. Desalination Water Treat. 2019, 151, 189-198. [CrossRef] 